\title{
Are There Marketed Optimal Options for Female Sexual Pain? A Review and Preliminary Evidence of a New Water - Based Vaginal Lubricant
}

\author{
Suárez-Almarza J*, Palma- Santisteban M, Velasco-Ortega S and Nieto-Magro C \\ ITF Research Pharma S.L.U, Madrid, Spain
}

Submission: March 08, 2018; Published: April 09, 2018

*Corresponding author: Javier Suárez-Almarza, Pharm, BSND, ITF Research Pharma S.L.U, Calle San Rafael 3, 28108 Alcobendas, Madrid, Spain. Tel: +0034916572323; Email: jsuarez@itfsp.com

\section{Introduction}

Female sexual pain (FSP) disorders are one type of female sexual difficulty that affects women's sexual and reproductive health and they are poorly understood and often misdiagnose [1]. They have a significant negative impact on a woman's health, self-esteem, relationships, quality of life, and work productivity. It can be difficult to identify a definitive cause of pain. The aim of this review was to investigate recommendations of treatments for sexual pain caused by lack of lubrication and to present the results of an identified treatment developed in accordance with latest evidence from scientific societies.

\section{Outcomes}

FSP is a common, distressing complaint in women of all ages that is under recognized and undertreated [2]. Definitions and terminology for female FSP are currently being debated. While some authors have suggested that FSP is not per se a sexual dysfunction, but rather a localized genial pain syndrome, others adhere to using clearly sexually related terms such as dyspareunia and vaginismus [2]. Sexual pain can be mild to severe, generalized or localized and can be present for any amount of time. Reported prevalence estimates for female sexual dysfunction and pain are challenging to determine as study designs may be influencing and contributing to the wide variation in published estimates [3]. The population prevalence of painful sex (dyspareunia) is estimated to vary from 3 to $18 \%$ globally and lifetime estimates range from 10 to $28 \%$ and approximately $15 \%$ of women might finally develop chronic dyspareunia $[4,5]$.

Decrease of vaginal lubrication is highly likely to be the main cause of dyspareunia when no other diagnosed vaginal related pathology is present. Reasons for such decrease are numerous and include advancing age, hormonal changes, menopause, breastfeeding, stress, other conditions, and iatrogenic causes such as radiation and chemotherapy treatment and antidepressant use [6]. First line treatments would include vaginal moisturizers and lubricants [7]. Although lubricants and moisturizers have demonstrated effectiveness, they differ in terms of their composition, and certain individual components may be of concern in specific situations. Therefore, it is important to choose the most appropriate lubricant or moisturizer to best suit the needs of the individual patient [6]. Different types of lubricants might be used being water-based lubricants associated with fewer genital symptoms in women, compared with siliconebased as well as having the advantage of being non-staining [6].

Lubricants are effective in relieving discomfort and pain during intercourse. Vaginal lubricants ease sexual intercourse as they minimize friction during penetration and neutralize vaginal $\mathrm{pH}$ to help sperm survival. According to $\mathrm{WHO}$, the $\mathrm{pH}$ of the healthy vagina is normally in the range 3.8-4.5 and ideally a vaginal lubricant should have a $\mathrm{pH}$ of about 4.5. The preservation of water-based lubricants is easier if the $\mathrm{pH}$ is maintained below 7. For these reasons the $\mathrm{pH}$ recommended for this type of lubricants is 7 or less [8].

Following WHO's review, it is remarked that most commercial lubricants have high osmolalities(2000-6000 m0sm/kg). By comparison, the normal osmolality of female vaginal secretions is $260-290 \mathrm{mOsm} / \mathrm{kg}$ and in human semen it is $250-380 \mathrm{mOsm} /$ $\mathrm{kg}$. Ideally, the osmolality of a lubricant should not exceed 380 $\mathrm{mOsm} / \mathrm{Kg}$ to minimize any risk of epithelial damage. Given that most commercial lubricants significantly exceed this value, imposing such a limit at this time could severely limit the options for sourcing personal lubricants for sector procurement and a need of developing optimal treatments is foreseen [8].

A preliminary clinical study with a water-based vaginal lubricant (Suzanne Lubricante $\AA /$ Ainara Lubricante $\AA$ ), developed considering the above referenced specifications 


\section{Global Journal of Reproductive Medicine}

(osmolality<380 mOsm/Kg and $\mathrm{pH} 6.5$ ), was conducted in female adult subjects treated for 3 weeks. A total of 20 female subjects, aged between 18 and 70 years old, with dry intimate are and $100 \%$ of sensitive intimate skin were recruited. Treatment was applied by the subject herself before sexual intercourse and in case of failure to comply with 2 sexual intercourses in one week, the product was applied twice weekly. Clinical examinations by dermatologists and gynecologists on Day 1 and Day 22 as well as a questionnaire to be filled in by the subject on Day 22 evaluated the acceptability and tolerability of the product. Analysis of the results obtained revealed on the whole a very good acceptability Table 1: Itching on the intimate zone. of the investigational product in all subjects as regards irritation or discomfort. No abnormal clinical sign was observed by the Dermatologists and/or Gynecologists, after 3 weeks of application. No subject indicated to have had or observed, during the study, any cutaneous reaction, irritation or discomfort. Itching in the intimate zone was also tested according to a scale from 0 (few itching) to 8 (lot of itching) together with dryness on the intimate zone scored from 0 (few dryness) to 8 (lot of dryness). Significant statistical decrease of both symptoms were observed between Day 1 and 22 as shown in Table $1 \& 2$.

\begin{tabular}{|c|c|c|c|c|c|}
\hline \multicolumn{2}{|c|}{} & \multicolumn{2}{|c|}{ Mean and Standard Deviation (S.D) } & \multirow{2}{*}{$\begin{array}{c}\text { Probability P: } \\
\text { Wilcoxon Test }\end{array}$} & $\begin{array}{c}\text { Variation } \\
\text { Percentage \# }\end{array}$ \\
\hline Itching on the intimate zone & $\mathbf{n}$ & D1 Initial value & D22 & $\mathbf{0 . 0 0 0 1}$ & $-94 \%$ \\
\hline
\end{tabular}

In bold: Significant statistical probability: $\mathrm{p}<0.05$.

\# Variation regarding the initial values

Table 2: Dryness on the intimate zone.

\begin{tabular}{|c|c|c|c|c|c|}
\hline & \multirow[b]{2}{*}{$\mathbf{n}$} & \multicolumn{2}{|c|}{ Mean and Standard Deviation (S.D) } & \multirow{2}{*}{$\begin{array}{l}\text { Probability P: } \\
\text { Wilcoxon Test }\end{array}$} & \multirow{2}{*}{$\begin{array}{c}\text { Variation } \\
\text { Percentage \# }\end{array}$} \\
\hline & & $\begin{array}{c}\text { D1 } \\
\text { Initial value }\end{array}$ & D22 & & \\
\hline Dryness on the intimate zone & 20 & $5.70 \pm 1.22$ & $2.15 \pm 1.90$ & 0.0001 & $63 \%$ \\
\hline
\end{tabular}

In bold: Significant statistical probability: $p<0.05$

\# Variation regarding the initial values

Table 3: Efficacy and Acceptability.

\begin{tabular}{|l|c|}
\hline Suitable product for the skin of the intimate area & $100 \%$ \\
\hline Pleasant application of the product & $95 \%$ \\
\hline Easy application of the product & $95 \%$ \\
\hline Pleasant texture of the product & $95 \%$ \\
\hline The product has a lubricant effect of the intimate zone & $95 \%$ \\
\hline The product helps to relieve the dryness of the intimate Zone & $100 \%$ \\
\hline The product acts as your natural lubrication & $90 \%$ \\
\hline Efficient product from the beginning & $90 \%$ \\
\hline The lubricant effect appears immediately after the application & $100 \%$ \\
\hline The lubricant effect duration is prolonged during all the sexual intercourse & $90 \%$ \\
\hline You would use this product in habitual use in your sexual intercourse & $90 \%$ \\
\hline The use of this product improves the sexual intercourse & $95 \%$ \\
\hline The product improves the penetration and it soothes the comfort during the sexual intercourses & $95 \%$ \\
\hline The product provides a comfort sensation & $95 \%$ \\
\hline The product provides a lasting comfort sensation & $85 \%$ \\
\hline The product does not stain on the clothes after its application & $100 \%$ \\
\hline Globally, l like the product & $90 \%$ \\
\hline Your partner likes the product from "a lot" to “enough" & $85 \%$ \\
\hline Your partner finds that the product is pleasant & $85 \%$ \\
\hline By comparing with the product generally used, the subject found her skin “ just as good” to “better” & $100 \%$ \\
\hline
\end{tabular}




\section{Global Journal of Reproductive Medicine}

The evaluation of the efficacy and acceptability questionnaire showed a positive judgement and a favorable appraisal of these subjects and their partners for all assessed criteria as shown in Table 3. Between its favorable effects, it must be outlined its immediate lubricant effect after application, together with its prolonged duration throughout all the sexual intercourse, particularities not always achieved by this type of products. Subjects were also asked about their partners' acceptability of the product, obtaining a very positive result.

\section{Conclusion}

This brief review highlights the importance of treating sexual pain associated with lack of lubrication with suitable products. Scientific societies have a view on this matter and identify certain characteristics in order to choose the most appropriate alternative. Currently there are many different options available on the market but it was addressed that many of them do not comply with their recommendations. The study describes a product, developed with ideal osmolality and $\mathrm{pH}$, which provides a very good efficacy in improving symptoms like itching and dryness besides the optimal subject's acceptability.

\section{References}

1. Al-Abbadey M, Liossi C, Curran N, Schoth DE, Graham CA (2016) Treatment of Female Sexual Pain Disorders: A Systematic Review. J Sex Marital Ther 42(2): 99-142.

2. Fugl-Meyer KS, Bohm-Starke N, Fugl- Meyer A, Parish S, et al. (2013) Standard operating procedures for female genital sexual pain. J Sex Med 10(1): 83-93.

3. Hayes RD, Bennett CM, Dennerstein L, Taffe JR, Fairley CK (2008) Are aspects of study design associated with the reported prevalence of female sexual difficulties?. Fertil Steril 90(3): 497-505.

4. Weijmar Schultz W, Basson R, Binik Y, Eschenbach D, Wesselmann U, et al (2005) Women's sexual pain and its management. J Sex Med 2(3): 301-316.

5. Mitchell KR, Geary R, Graham CA, Datta J, Wellings K, et al. (2017) Painful sex (dyspareunia) in women: prevalence and associated factors in a British population probability survey. BJOG 124(11): 1689-1697.

6. Edwards D, Panay N (2016) Treating vulvovaginal atrophy/ genitourinary syndrome of menopause: how important is vaginal lubricant and moisturizer composition?. Climacteric 19(2): 151-161.

7. (2013) Management of symptomatic vulvovaginal atrophy: 2013 position statement of The North American Menopause Society. Menopause 20(9): 888-902.

8. http://apps.who.int/iris/handle/10665/76580

\section{Your next submission with Juniper Publishers will reach you the below assets}

- Quality Editorial service

- Swift Peer Review

- Reprints availability

- E-prints Service

- Manuscript Podcast for convenient understanding

- Global attainment for your research

- Manuscript accessibility in different formats

( Pdf, E-pub, Full Text, Audio)

- Unceasing customer service

Track the below URL for one-step submission

https://juniperpublishers.com/online-submission.php 